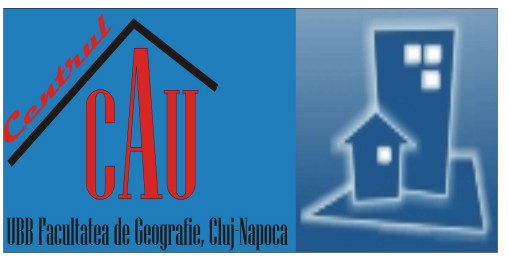

\title{
What Does Unsustainable Urban Sprawl Bring? Spatial Patterns Analysis of Built Environment in Cluj Metropolitan Area
}

\author{
Elena-Manuela BÎRSĂNUC', Titus-Cristian MAN ${ }^{*}{ }^{2}$, Dănuț PETREA3 \\ ${ }^{*}$ Corresponding author \\ ${ }^{1}$ Babeş-Bolyai University, Faculty of Geography, Cluj-Napoca, ROMANIA \\ ${ }^{2}$ Babeş-Bolyai University, Faculty of Geography, Department of Regional Geography and Territorial Planning, Cluj-Napoca, ROMANIA \\ 3 Babeş-Bolyai University, Faculty of Geography, Department of Physical and Technical Geography, Cluj-Napoca, ROMANIA \\ E-mail: elena.birsanuc@ubbcluj.ro, titus.man@ubbcluj.ro,danut.petrea@ubbcluj.ro \\ DOI: 10.24193/JSSP.2019.2.05 \\ https://doi.org/10.24193/JSSP.2019.2.05
}

K e y w o r d s: land use conversion, metropolitan area, SAVI, spatial patterns of urbanization, population growth rates, urban sprawl

\begin{abstract}
A B S T R A C T
Urban sprawl and population growth are the main triggers of land use reconversion around big cities. Due to the expansion of metropolitan areas, many land use categories (grasslands, arable lands, forests, pastures) have been transformed in living spaces. Determining the built-up area growth rate from satellite images, in correlation with demographics and dwellings data, leads to a better comprehension of sustainable urban development and the negative effects of chaotic urbanization. This study analyses the built-up area expansion growth rate in Cluj Metropolitan Area in 1991-2017 using the normalized difference built-up index and soil-adjusted vegetation index applied on Landsat imagery. Results highlight different spatial patterns within the studied area, based on the correlation between the growth rates of built-up area expansion and demographic data. The land use types most impacted by the urban sprawl are meadows and arable lands near the metropolitan centre and grassland in areas located at the periphery of the metropolitan area.
\end{abstract}

\section{INTRODUCTION}

Due to the increasing number of population that generates high rates of concentration with an impact on infrastructure and natural resources, metropolitan areas are the most attractive urban spaces for territorial expansion. Drivers and land use policies of these land changes require efficient and prudent approaches in order to suggest a more efficient strategy for land use management (Vaz and Nijkamp, 2015).

Areas located in the neighbourhood of urban zones are the most exposed to land use change as a result of urban expansion. Often, these areas are providing society with essential agroecosystems such as forests, grasslands, farmlands, therefore the consequences of urbanization being both positive and negative (Li et al., 2016; Zhou et al., 2018; Zhang et al., 2017).

Scholars have documented the various effects of land transition from various other uses to the urban one, as a result of urbanization (Wang et al., 2018) with a special focus on: economic, environmental, and social consequences (Benedek et al., 2018; Chen et al., 2016; Kantakumar et al., 2016; Parece and Campbell, 
2013; Pickett et al., 2011); hydrologic effects of urban expansion leading to increased runoff as a consequence of natural lands conversion (Grimm et al., 2000; Li et al., 2013); environmental effects of land use management on air quality, water and soil systems (DeFries et al., 2010; Rojaset al., 2013); land-use change effect on food security (Jiang et al., 2012; Song et al., 2015); impact of urban expansion on life quality (Frenkel and Ashkenazi, 2008). The positive consequences of urbanization are primarily financial, commercial and educational leading to economic growth in a certain region (Ameen and Mourshed, 2017; Seto et al., 2011; Ionescu-Heroiu et al., 2013a; Cristea et al., 2017; Ionescu-Heroiu et al., 2013b).

As metropolitan areas all over the world continue to expand in terms of population and urbanized areas (many of them at unprecedented rates (Jiao, 2015), land use transitions have drawn society's attention, general media and the scientific community.

In the last years satellite remote sensing was adopted as a cost-effective technology for urban expansion monitoring based on its ability to discriminate among various land-use types, particularly in differentiating built-up lands from non-built-up lands $(\mathrm{Xu}, 2008)$ and also due to long-term image archives availability (Osgoueiand Kaya, 2017). However, many scholars have reported unsatisfactory degrees of accuracy produced using the multi-spectral classification (Gomarasca et al., 1993; Thyagharajan and Vignesh, 2017). Therefore, most of the studies have combined various techniques to improve the methodology of built-up area extraction from satellite images such as those based on the development and usage of spectral indices: Normalized Difference Vegetation Index, Soil-Adjusted Vegetation Index, Normalized Difference Built-up Index, Built-Up Area Index (Zha et al., 2003; Osgoueiand Kaya, 2017). However, based mostly on their properties to estimate the amount of vegetation depicted from the satellite images (Zhouand Ouyang, 2013), very often these indices fail to provide accurate information about builtup areas. Moreover, scholars have remarked the lack of precision in estimating general trends in land-use transition from agricultural areas to urbanized ones (Song et al., 2015) and the requirement to include other statistical variables in the geospatial models to better estimate evolution trends (Seto et al., 2011; IonescuHeroiu et al., 2013a).

In Romania, monitoring of urban sprawl using satellite images was documented by several scholars with a focus on determining the land use change in different areas over a specific period (Huzui et al., 2013; Câmpianu and Corodescu, 2013). Also, the characteristics and typologies of urban sprawl were approached in the context of residential development (Suditu et al., 2010) concluding that the main triggers of urban sprawl consist of a combination of factors including, but not limited to, real estate pressure, economic activities, transport infrastructure, and others.

As for sustainable land use management in metropolitan areas, it consists in coordinating spatial, temporal and sector-oriented components of the local and regional policies for territorial development. The key features of this process include sustainable housing, affordable land, convenient infrastructures, welllocated social and economic facilities with decent service areas, and other territorial amenities (Engelke and Vancutsem, 2010). However, most of the newly urbanized areas in the metropolitan territories of Romania have faced an anarchic development process (Benedek et al., 2018) and the advantages of periurbanisation/urban sprawl were dramatically reduced. In this context, the conversion of agricultural land use into a diversified, yet a more urbanized one, is rather unsustainable (Mancebo, 2008).

Therefore, the main objective of this study is to determine the impact built-up area expansion has on agricultural land, by defining the growth rate and correlating it with data on demographics and dwellings (number of building permits) in order to determine which agricultural land cover categories are most affected by the urbanization process.

In addition, the present study aims to estimate a spatial pattern scenario of urban expansion based on the characteristics of population age groups that will be concentrated in the metropolitan area.

This paper is structured as follows: the study area and methodological approaches are presented in Section 2. Section 3 is dedicated to results and discussion on the land use change analysis. Lastly, the conclusions are summarized in Section 4.

\section{THEORY AND METHODOLOGY}

\subsection{Study area}

Cluj-Napoca is the most important city of Transylvania and the county seat of Cluj County, located in the north western region of Romania. Cluj Metropolitan Area (CMA) consists of 18 territorial administrative units (TAUs) in the neighbourhood of Cluj-Napoca city. The inclusion of TAUs in the metropolitan area is based on freewill; therefore, CMA is defined by a very dynamic boundary depending on the individual decision of each TAU.

The economic and demographic differences between the constituent settlements of the metropolitan area derive from their proximity to the city of ClujNapoca. Thus, we note the territorial division of CMA into two main zones (Fig. 1): Zone A extending along the Someș River and the main transport axis (National road 1 (DN1) - European 6o (E6o), National road $1 \mathrm{C}$ (DN1C) - European 570 (E570); and the main railway 
route) and including 6 TAUs; and Zone B consisting of other 12 TAUs. Accordingly, land use changes and builtup area expansion in the two zones of the CMA also have a distinctive trend and impact.

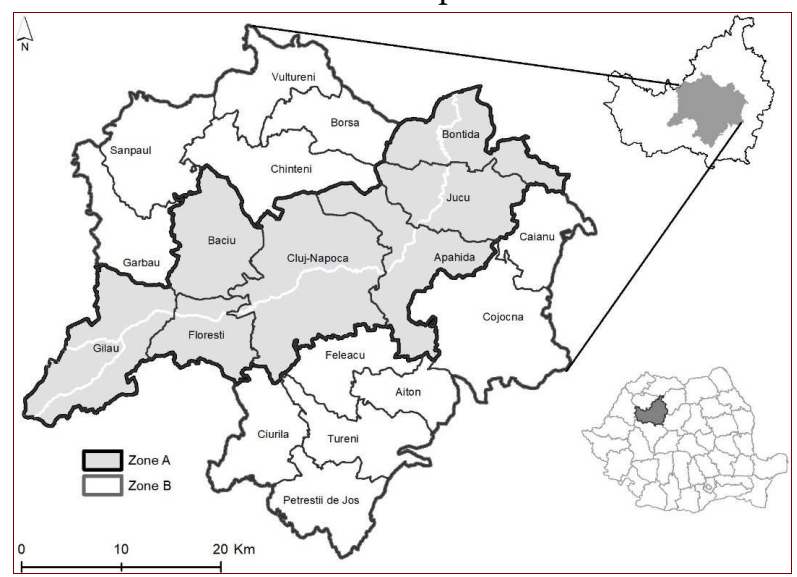

Fig. 1. Location of the study area.

\subsection{Data and methods}

The data used for determining the built-up expansion growth rates was derived from Landsat satellite imagery database provided by the United States Geological Survey (USGS), including images from June 1991 until June 2017, both Landsat Thematic Mapper and Landsat Enhanced Thematic Mapper+ (Table 1).

Table 1. Landsat data (TM: Thematic Mapper; ETM+: Enhanced Thematic Mapper Plus).

\begin{tabular}{ll|l} 
No. & Acquisition date & Landsat sensor type \\
\hline 1. & $\begin{array}{l}\text { 19 June } 1991 \\
\text { 28 June } 1997 \\
\text { 2. }\end{array}$ & 22 August 1997 \\
3. & 16 May 2002 & TM \\
4. & 25 May 2002 & April 2006 \\
5. & 17 July 2010 & TM \\
6. & 02 June 2017 & ETM+ \\
\hline
\end{tabular}

The ability of spectral vegetation indices, Normalized Difference Vegetation Index (NDVI) and Soil-Adjusted Vegetation Index (SAVI) to estimate the vegetation cover with a high degree of accuracy have determined their rapid adoption by scientists and conducted to a longstanding history of their use in various studies. NDVI and SAVI values range between 1 and +1 , a value of -1 indicating absorbing areas (water bodies) and +1 reflecting areas (green forests). In addition, SAVI uses a soil brightness correction factor to better differentiate bare lands from built-up areas. Often, these indices are analyzed in combination with other spectral characteristics in order to determine water bodies (Normalized Difference Water Index NDWI), built-up areas (Normalized Difference Built-Up Index - NDBI; Urban Index - UI, BUAI).

The spectral indices employed in the present study to accurately determine built-up areas and urbanized areas extension were: NDVI (1), SAVI (2), and NDBI (3).

$$
N D V I=\frac{N I R-R E D}{N I R+R E D}
$$

where:

$N I R$ - spectral reflectance measurements in near-infrared zones;

$R E D$ - spectral reflectance measurements in Red (visible) band.

$$
S A V I=\frac{N I R-R E D}{N I R+R E D+L} \times(1+L)
$$

where:

NIR - spectral reflectance measurements in near-infrared zones;

$R E D$ - spectral reflectance measurements in Red (visible) band; $\mathrm{L}=$ soil brightness correction factor.

$$
N D B I=\frac{S W I R-N I R}{S W I R+N I R}
$$

where:

$N I R$ - spectral reflectance measurements in near-infrared zones;

$S W I R$ - spectral reflectance measurements in short wave near-infrared zones.

Before processing, images were validated for the accuracy and errors resulting from the failure of the Landsat 7 ETM+ Scan Line Corrector (Markham et al., 2004) and were corrected using Landsat Toolbox from ArcGIS. The official land use/land cover dataset provided by the National Agency for Cadastre and Land Registration was used as reference data to calibrate classifications, and spectral reflectance thresholds were established for each of the land-use types. In order to determine the spatial patterns and estimate the general land-cover trends in CMA, the land use reclassification results were further included in the analysis in combination with statistical data from the National Institute of Statistics (NIS), such as Permanent Resident Population by age (POP107D) (1992-2018), Building permits (LOC108B) (2002-2017), and Land Fund Area by usage (AGR101B) (1990-2014). Pearson correlation matrix was derived to determine linear correlations between variables and to establish crossparametric trends. The interactions among variables 
were further analysed based on R-squared values and statistical significance (probability values). Digital image processing, geospatial and geostatistical analyses were completed using ERDAS (Hexagon Geospatial, Madison, AL), ArcGIS (ESRI, Redlands, CA), SPSS (IBM Analytics), and Microsoft Office suite.

\section{RESULTS AND DISCUSSION}

\subsection{Built-up area growth rate through spectral indices}
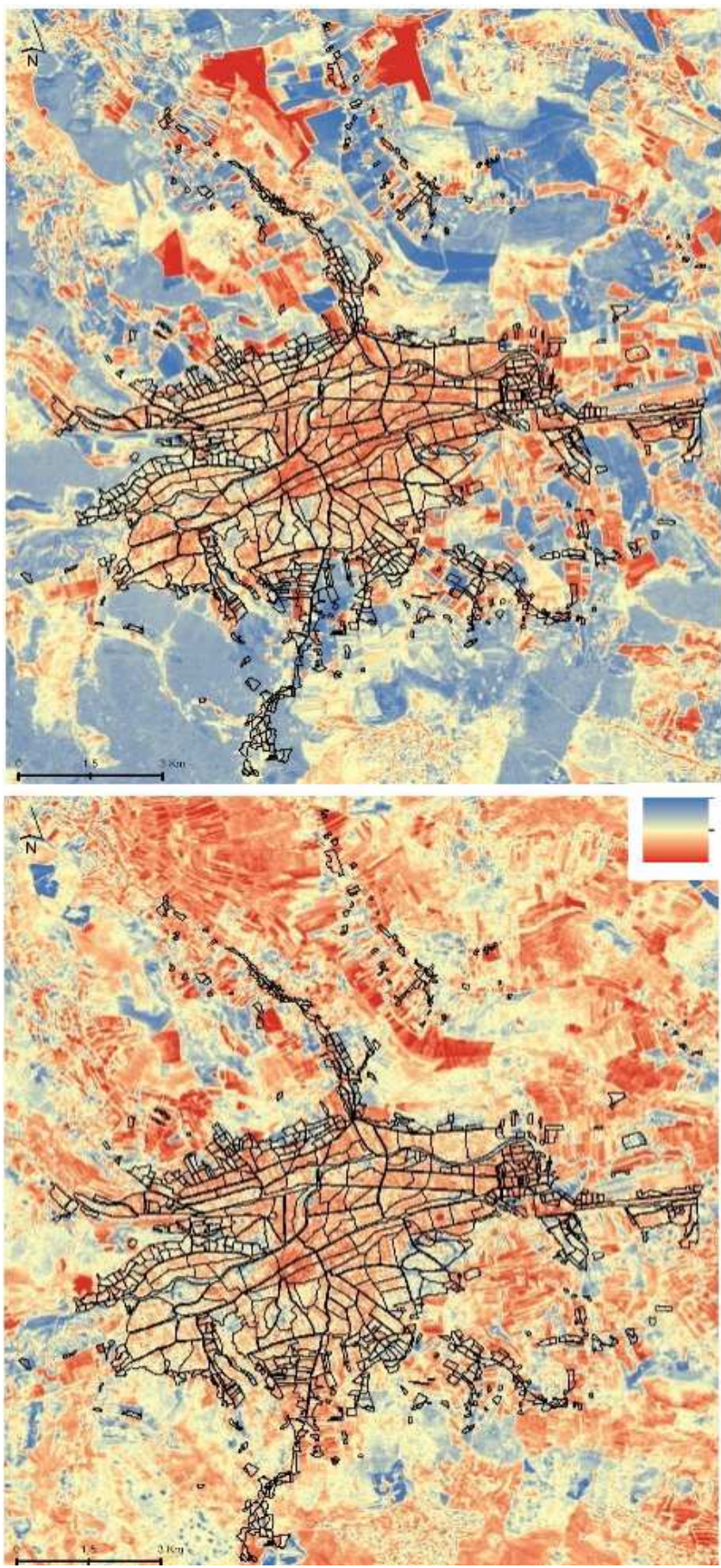

The analysis was firstly based on the usage of NDBI in order to determine the built-up expansion growth rate of CMA over the period 1990-2017. However, this index is unable to clearly distinguish between built-up area and bare soil (Zhaet al., 2003; Garcia and Perez, 2016) due to similar spectral response of these land categories in the SWIR and NIR wavelengths.

NDBI returns reliable results in compact urban zones, whereas in urban areas with green spaces and trees the accuracy of classification is low (Fig. 2).
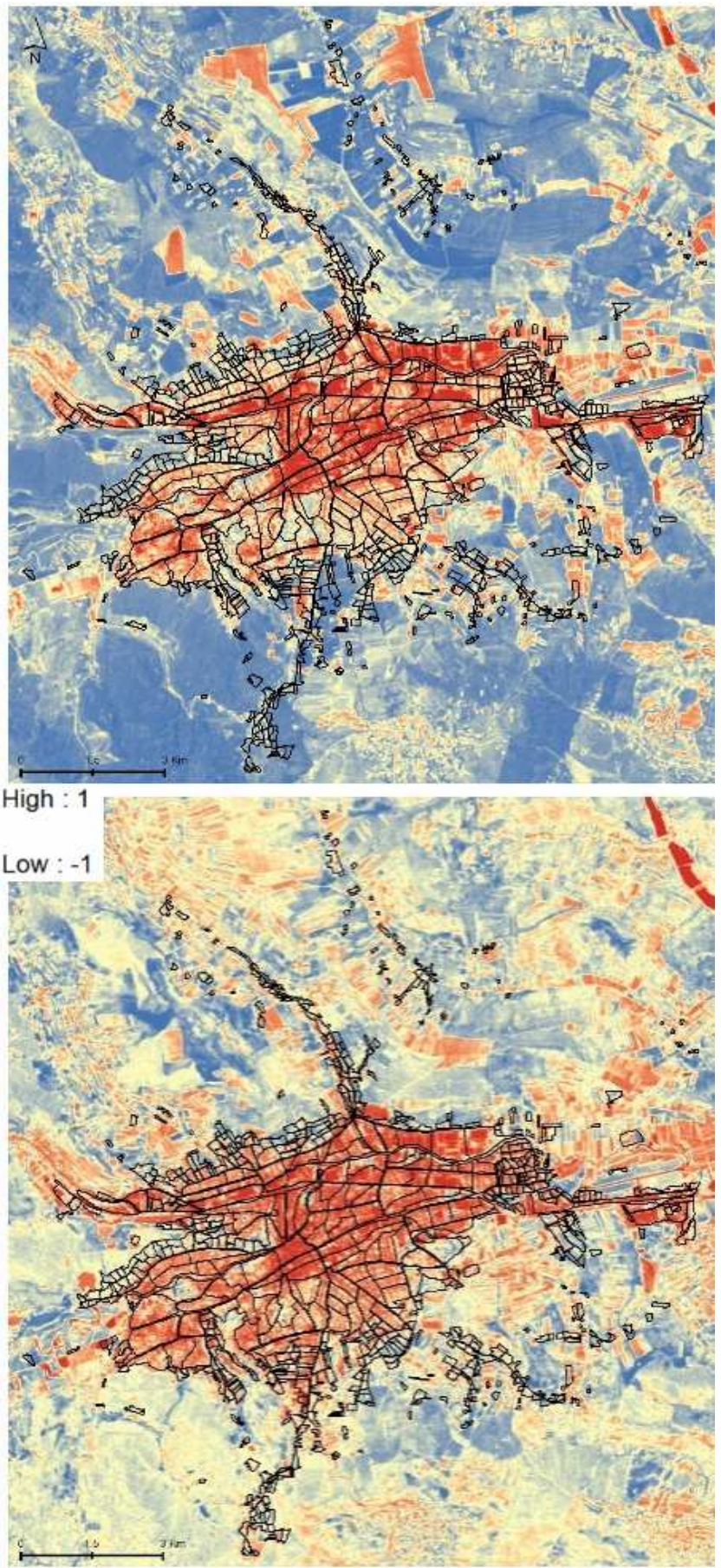

Fig. 2. NDBI 1991 (upper left); SAVI 1991 (upper right); NDBI 2006 (bottom left); SAVI 2006 (bottom right).

Vegetation indices (NDVI, SAVI) can be used as proxies in the process of land-use types discrimination (Garcia and Perez, 2016) so as to improve the classification accuracy. 
The resulting classification returned a better distinction between these two types of land use (Fig. 2) when SAVI was applied and these results were used as inputs for the built-up area growth rate analysis.

The default value of soil brightness correction factor (L) used in SAVI formula (2) was 0.5. Regularly, the value of $L$ depends on the vegetation density, as for very high vegetation areas the value of $L$ will be o, and in the case of regions with no vegetation the $L$ value will be 1 (Huete, 1988). For this study, 0.5 was the most appropriate value for the soil brightness correction factor, as the density of vegetation is much diversified within the territory.

The reclassification of SAVI resulted in four main categories of land use: continuous urban areas (for areas completely occupied by buildings and construction sites); discontinuous urban areas (including mainly urban areas, with a limited number of pixels representing vegetation or other categories of land use); mixed areas (where buildings and vegetation cover similar areas) and pastures and forests (including all land plots outside urban areas).
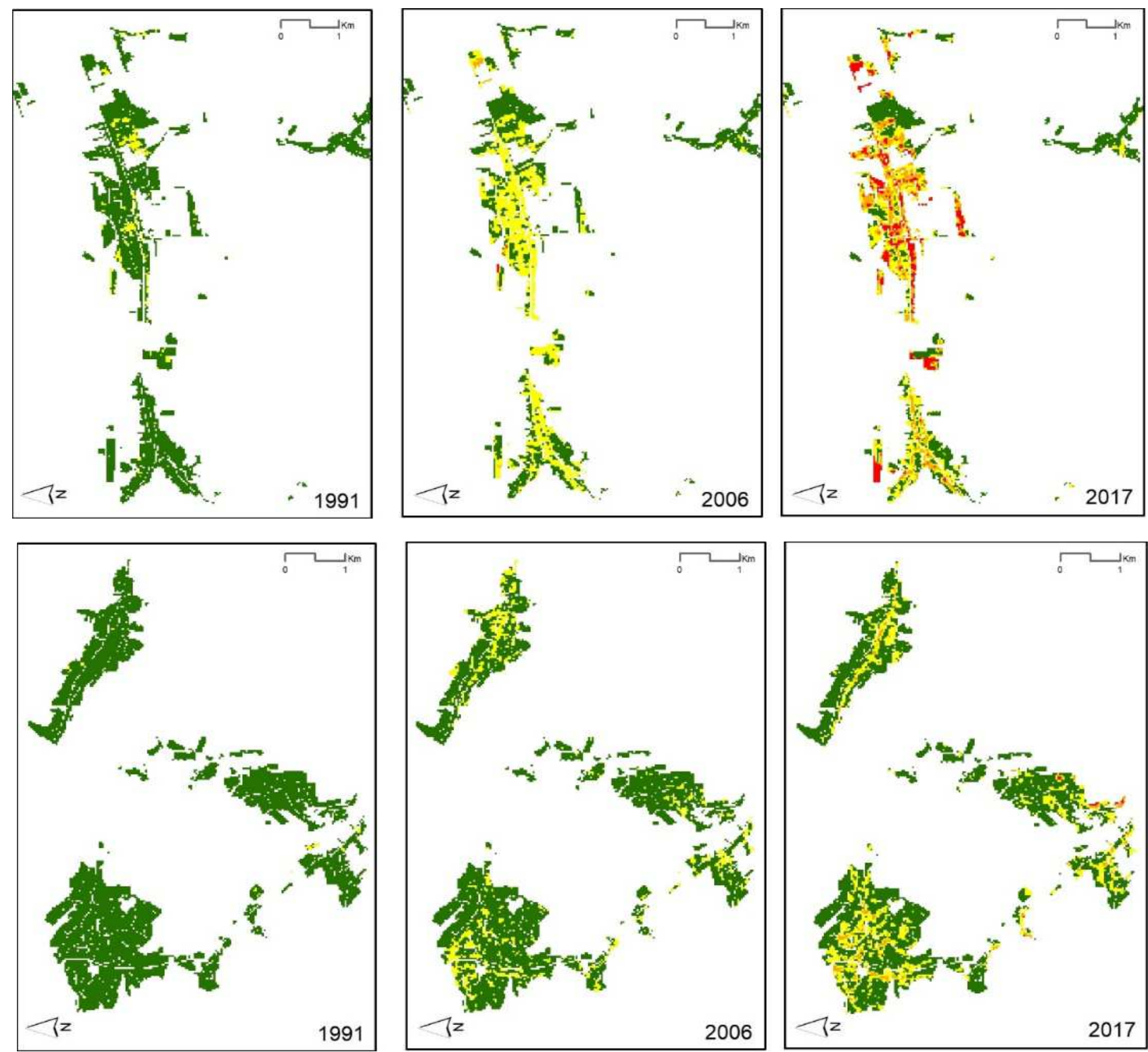

Land use categories (SAVI)

Continous urban area

Discontinous urban area

Mixed area

Pastures and forests

Fig. 3. Built-up expansion examples in Zone A (up) and Zone B (down) of CMA.

An accuracy assessment process was conducted by setting the threshold for the reclassification process using the official land cover dataset provided by the National Agency for Cadastre and Land Registration. Depending on the climate of the study area, various threshold values for SAVI have been used in previous studies. Thus, in areas with low vegetation cover rates, the SAVI threshold values are 
included in narrower interval (-0.07 ... -0.05 for urban areas), aiming to differentiate bare lands from built-up areas (Alqurashi and Kumar, 2016). However, in areas with mixed land cover, wider pixel values intervals proved to be necessary to better discriminate built-up areas from other land use types. Therefore, the threshold values selected for the area of this study range from -0.5 to -0.2 for Continuous Urban Areas, -0.2 to o for Discontinuous Urban Areas, 0.1 to 0.2 for Mixed Areas and up to 0.3 to 0.8 for Pastures and Forests land category. The reclassified images highlight great differences between the administrative units from Zone A of the metropolitan area compared to those included in Zone B, regarding the number of pixels for each of the four land use categories. Thus, the built-up area growth rate proves an accelerated urbanization process for Zone A of CMA (Fig. 3), with rates ranging from $59.67 \%(1991-2002)$ to $516.88 \%(2002-2010)$ and 15.93\% for the 2010-2017 period.

Although the built-up area growth rates for Zone B (Fig. 3) of the CMA are higher compared to the rates registered in Zone A (30.43\% in 1991-2002; 985.31\% in 2002-2010; and 54.60\% in 2010-2017), the highest density of new buildings is concentrated in the 6 TAUs included in zone A, whereas the growth rates for the TAUs in Zone B are scattered on a much larger territory, defining a slow urbanization process.

As the main centre of the metropolitan area, Cluj-Napoca city registered an accelerated growth rate of built-up area from $1991\left(9.5 \mathrm{~km}^{2}\right)$, to $2006\left(36 \mathrm{~km}^{2}\right)$, until $2017\left(71 \mathrm{~km}^{2}\right)$. The spatial pattern of expansion follows the main transport axis and changes the land use profile of the city surrounding areas (Fig. 4).

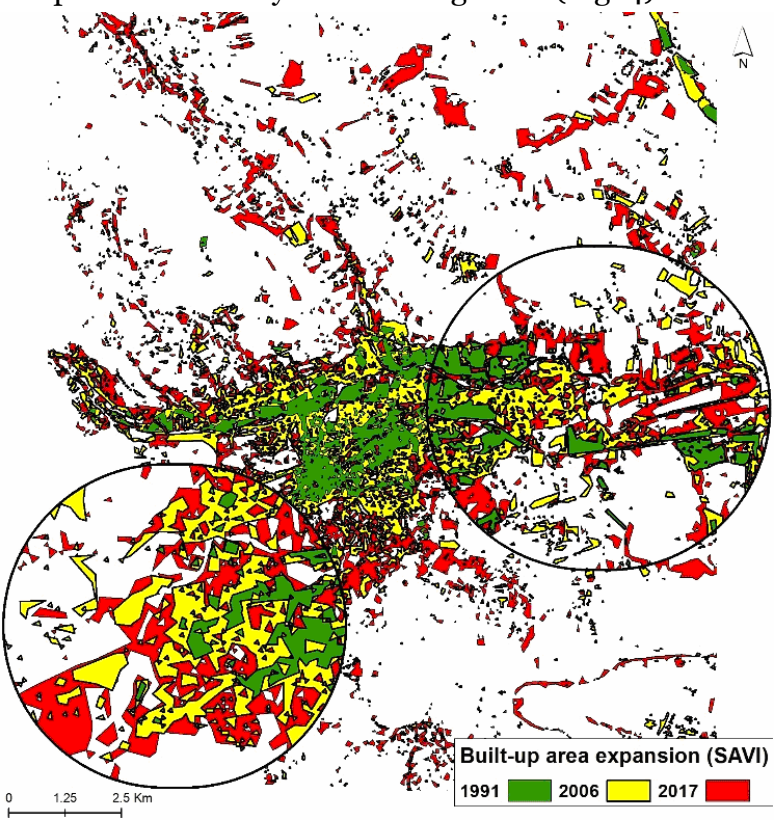

Fig. 4. Spatial patterns of built-up area expansion in Cluj-Napoca.

Land-use data were correlated with statistical indices in order to assess the spatial patterns of urban area extension in Cluj Metropolitan Area and estimate 126 future trends and the prospective impacts of urban sprawl.

\subsection{Urbanization patterns through demographic data}

The demographic evolution in Cluj Metropolitan Area has shown an ascending trend, especially in the last decade, with a population growth rate of $10.66 \%$. Analysed by age groups, population indicates a negative growth rate of the 20-29 age group (-25.07\%), while the 30-39 and 40-49 age groups register highly positive growth rates (47.44\%, respectively 41.66\%) (NIS, 2018). The analysis of Permanent Resident Population by age (1991-2017) outlines high concentrations of population in Zone A of the CMA (density values ranging from 74.89 to 1801.06 inhabitants $/ \mathrm{km}^{2}$ ) and lower concentrations in Zone B depending on the size of TAUs (density values ranging from 20.48 to 62.24 inhabitants $/ \mathrm{km}^{2}$ ) (NIS, 2018).

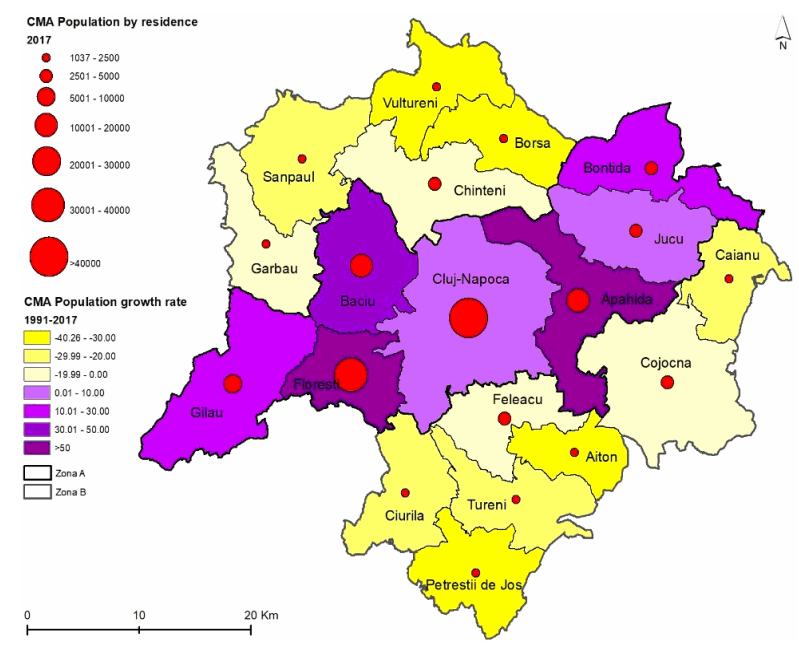

Fig. 5. Population by residence (2017) and growth rate (1991-2017) in Cluj Metropolitan Area.

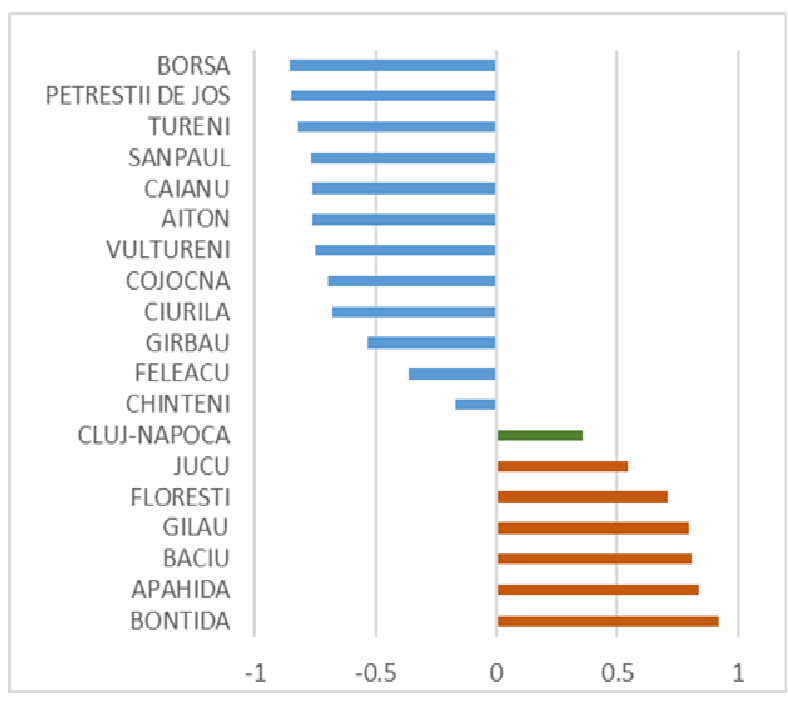

Fig. 6. Built-up area and population growth rates correlations (1991-2017) in Cluj Metropolitan Area. 
Population growth rate follows a similar spatial pattern: settlements along the Someş River in the neighbourhood of Cluj-Napoca (zone A) record positive and strong positive growth rates, while others (Zone B) register negative growth rate values, showing a decrease in the number of residents (Fig. 5).

The cross parametric trends of population and built-up areas derived using SAVI were correlated to better illustrate which of the TAUs are the most impacted by urban expansion. Correlation values are positive in Zone A fostering the hypothesis of urban expansion as a result of population increase (Fig. 6). All TAUs from Zone B of CMA returned negative values in the correlation matrix.

The determinants of urban growth do not consider either the effects of divergent rural and urban age and sex compositions (Jiang and O’Neill, 2018), or the contribution of migration to this process. However, the recent dynamics of economic development in the CMA, mainly the last-year transition from an industrial area to an IT hub, have triggered additional pressure on the real-estate sector.

In terms of age groups, this pressure was identified mostly in the case of population between 2050 of age, generating different spatial patterns of urbanization according to age and residence. The contribution of population from ages of 20 to 50 to the urbanization process in the CMA was analysed using the same methodology. Thus, TAUs with the highest built-up growth rate are the ones located close to the city of Cluj-Napoca, where the young population (2039) decides to reside, whilst the elder, although preferring to settle near the city, also have a consistent presence in Zone B of the metropolitan area (Fig. 7).

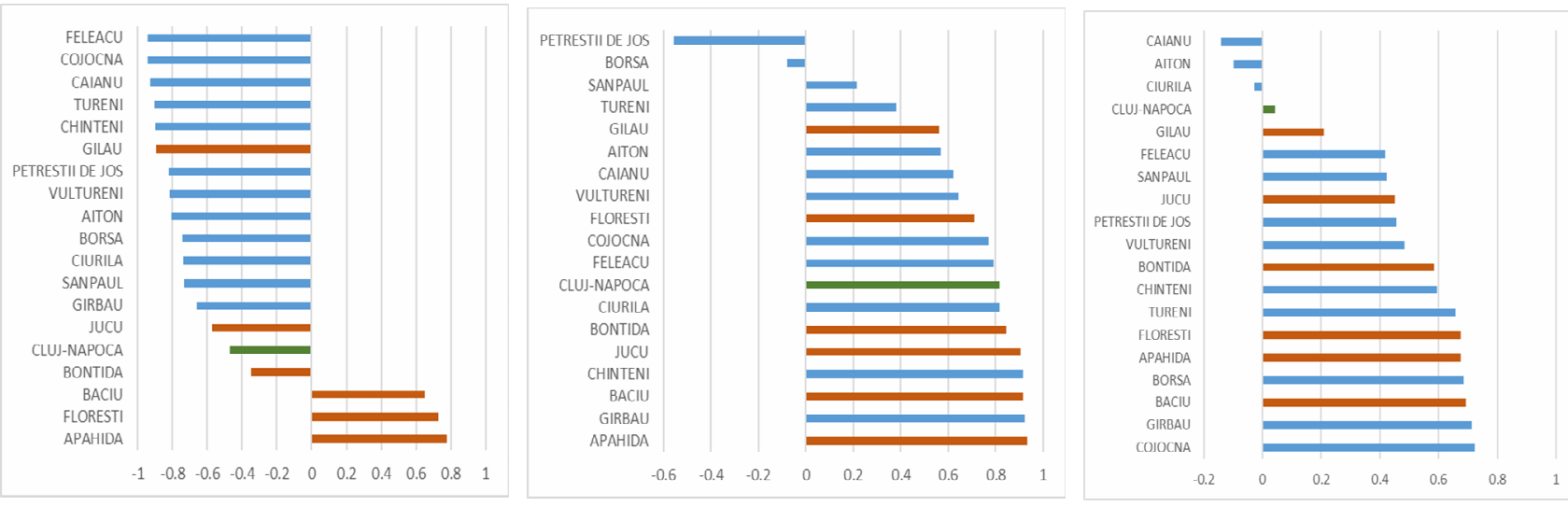

- Zone A Ione B - Metropolitan center

Fig. 7. Built-up area and age groups growth rates correlations (1991-2017): 20-29 (left), 30-39 (centre), $40-49$ (right) in Cluj Metropolitan Area.

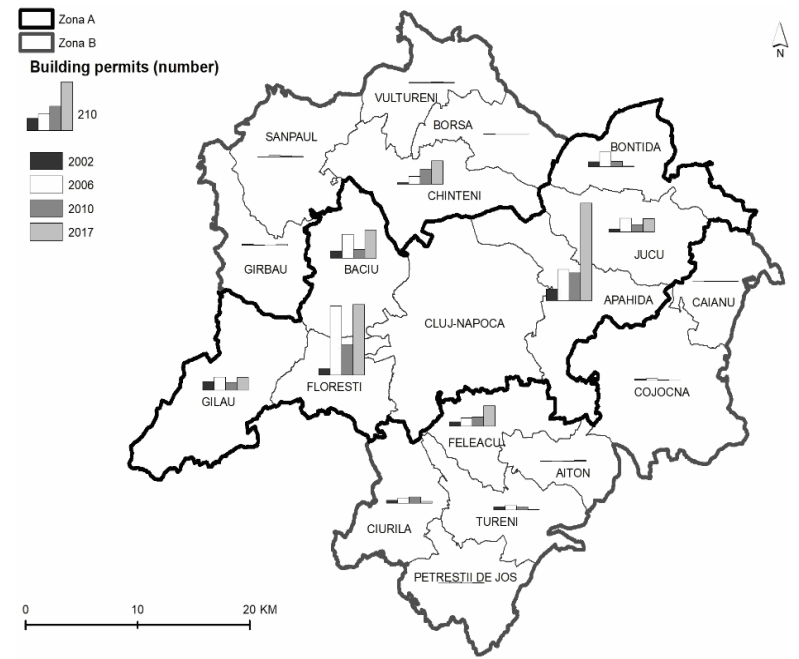

Fig. 8. Number of building permits issued in Cluj Metropolitan Area (2002-2017).

The analysis of the number of issued building permits returned significant results only when associated with the analysis of built-up growth rate. Otherwise, this number only quantifies building authorizations, without returning significant correlation results for urban sprawl. The column chart map generated from ArcMap v10.6.1 (Fig. 8) highlights the differences between the two main zones of the CMA regarding the building area expansion trend. This trend is a partial descriptor of the built-up area expansion analysis: first, it emphasizes the number of building projects that were legally approved, excluding the existing buildings, and second, as the built-up growth surface exceeds the area covered by building permits, it illustrates the territorial discrepancies between the two factors. Therefore, the highest built-up expansion pressure is registered in Zone A of the CMA through the number of building permits issued from 2002 until 2017 (Fig. 8). Unlike Zone B, the TAUs included in Zone A benefit from the presence of major transport axis and the Someş River, both factors contributing to the acceleration of the urbanization process in this region. However, it is a chaotic expansion of the built-up area due to poor administrative management of the territory (especially in the case of Florești: from 27 building permits in 2002 to 293 in 2006, 130 in 2010, and to 
300 in 2017). On the other hand, Zone B did not follow the same evolution trend, as only those TAUs bordering the city of Cluj-Napoca (Chinteni - from 7 in 2002, to 99 building permits in 2017, and Feleacu - from 19 in 2002, to 87 in 2017) registered a gradual but consistent increase in the number of new buildings (expressed in the number of building permits issued), while the rest of the TAUs in Zone B did not reflect similar trends, therefore sustaining the demographic data analysis results.

\subsection{Risk of lacking sustainability}

Along with the analysis on the expansion of built-up area, it is also important to determine which of the land categories were reconverted due to the urban sprawl phenomenon. The importance of results resides in assessing the level of sustainable development of the metropolitan territory. Chaotic urban sprawl will affect not only by crowdedness, but also by the changes incurred in agricultural ecosystems, green spaces and economic profile of certain areas. Moreover, among other possible effects we note the increase in the risk of landslide occurrence, climate change and reduction of economic benefits from land agricultural exploitation. The data regarding the Land Fund Area by usage (19902014) provided by the NIS were used to assess the main land use categories that have been impacted by the urbanization process. Overall, since 1991, Cluj Metropolitan Area has lost mostly grassland surfaces to built-up area expansion. However, the categories of agricultural land that were significantly reduced due to urbanization differ from Zone A to Zone B.

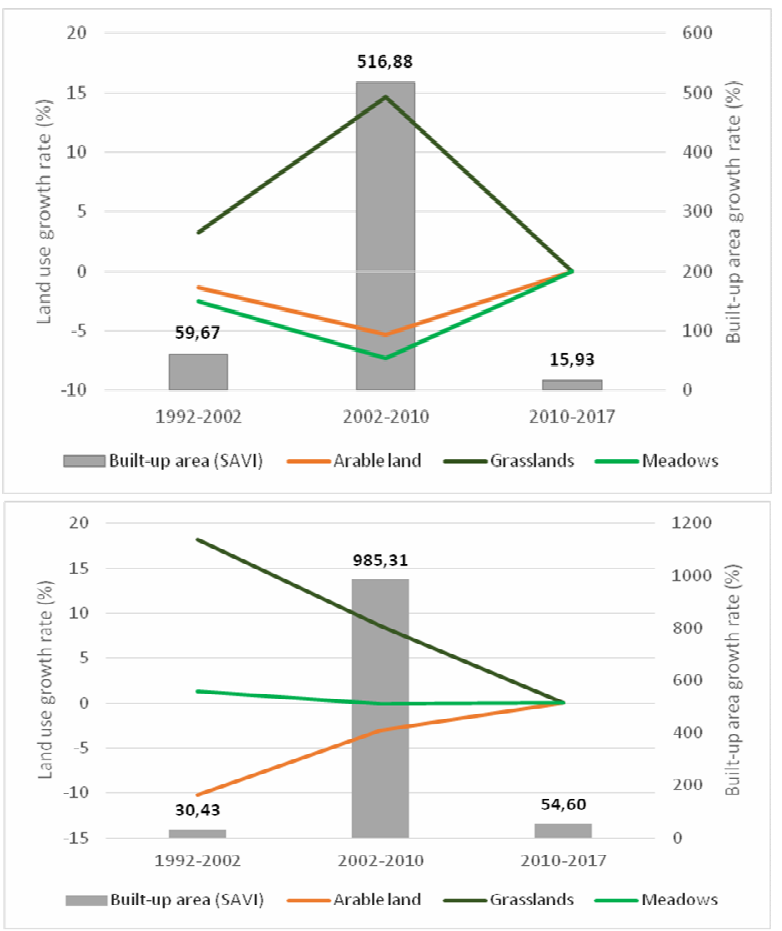

Fig. 9 Land reconversion trend in Cluj Metropolitan Area in Zone A (up) and Zone B (down).
On the one hand, Zone A has lost meadows and arable land, whereas in Zone B built-up areas have replaced mostly grasslands (Fig. 9). Due to the accelerated urbanization process along the Someș River, the arable land has already been significantly reduced and converted into built-up areas. As Zone B of the CMA is less influenced by the proximity of the city, the built-up area expansion process is slower, and the agricultural areas impacted by urban sprawl are much reduced compared to Zone A. Thus, despite the chaotic territorial management of the building process in Zone A, the lower rate of built-up growth for Zone B creates the context for sustainable development in order to avoid territorial inequalities. Furthermore, Figure 9 highlights a peak in the urbanization process from 2002 to 2010 , followed by a much more reduced growth rate explained by a slower urbanization rate (\%).

\section{CONCLUSIONS}

Satellite image processing and spectral indices were used to determine the built-up area expansion in Cluj Metropolitan Area in Romania aiming to illustrate the impact of urbanization process on agricultural systems. The usage of NDBI and SAVI applied on Landsat imagery of the last two decades allowed the extraction of land use change spatial patterns, with limited results due to the classification method. Data on demographics and dwellings were used to enhance the results of the analysis. In terms of population age groups, due to the IT economic profile of the area, 20 to 50 age groups were determined as the main trigerring factors for the urban sprawl phenomenon, in both urban and rural areas. Furthermore, newly developed residential areas were identified based on the number of building permits issued (2002-2017). Their correlation with the SAVI built-up area expansion results shows the distinctive level of urbanization in the CMA. Thus, two distinct zones with particular features in terms of population and urbanization degrees were identified based on the correlation of statistical data with the SAVI reclassification results: highly positive correlation results for the TAUs along the Someş River and negative correlation results for the Zone $\mathrm{B}$ of the CMA. Furthermore, land conversion trends were determined based on population age groups and their housing preferences. Therefore, if the current demographic trend continues as it is (increase of total population, decrease of 20-29 age group and increase at higher rates of $30-39$ and 40-49 age groups), the expansion of the built-up area will impact mostly the arable land and meadows in areas closer to the city (Zone A) and grasslands in other locations of the CMA (Zone B). In this context, encouraging the unsustainable urban sprawl process will contribute to the chaotic increase in the number of buildings number in the CMA. The trend analysis highlights future 
What Does Unsustainable Urban Sprawl Bring?

Spatial Patterns Analysis of Built Environment in Cluj Metropolitan Area

Journal Settlements and Spatial Planning, vol. 10, no. 2 (2019) 121-130

territorial discrepancies and gives administrative bodies reasons to frame new urbanization strategies that are sustainable and meet the population needs.

The usefulness of the study and the methods applied resides in the necessity of land management policies in order to reduce urban pressure and chaotic development and to maintain high living standards for the local population. In addition, having the hectic urban sprawl process, in disregard of any territorial development strategies, land use changes, mainly from green to built-up areas, weaken the environmental sustainability. The economic trend also has a significant impact on the demographic evolution, with both direct and indirect consequences on land use categories, as the areas with no major demographic or economic changes are also the areas least affected by the urbanization process.

\section{ACKNOWLEDGMENT}

This research was supported by PN-III-P4-IDPCE-2016-0729 and PN-III-P4-ID-PCCF-2016-0084 research grants at "Babeș-Bolyai” University, ClujNapoca, Romania. All authors contributed equally to this work.

\section{REFERENCES}

Alqurashi A. F., Kumar L. (2016), Spatiotemporal patterns of urban change and associated environmental impacts in five Saudi Arabian cities: A case study using remote sensing data. Habitat International, 58, 75-88. DOI: https://doi.org/10.1016/j.habitatint.2016.10.001.

Ameen R. F. M., Mourshed M. (2017), Urban environmental challenges in developing countries-a stakeholder perspective. Habitat International, 64, 1-10. DOI: https://doi.org/10.1016/j.habitatint.2017.04.002.

Benedek J., Ivan K., Rusu R., Hărănguș I., Man T., Dolean B., Moldovan C., Torok I. (2018), Studiu de fundamentare privind definirea zonelor periurbane din judeţul Cluj în scopul realizării planului de amenajare a acestora (Report on defining periurban areas in Cluj County for territorial development plan). [Report in Romanian]. URL: https://www.cjcluj.ro/ assets/uploads/Studiu\%2Ozonelor\%2operiurbane.pdf.

Cîmpianu C., Corodescu E. (2013), Landscape dynamics analysis in Iasi Metropolitan Area (Romania) using remote sensing data. Cinq Continents, 3 (7), 1832.http://www.cinqcontinents.uv.ro/3/3_7_Cimpianu.pdf Chen J., Gao J. Chen, W. (2016), Urban land expansion and the transitional mechanisms in Nanjing, China. Habitat International, 53, 274-283. DOI: https://doi.org/10.1016/j.habitatint.2015.11.040.

Cristea M., Mare C., Moldovan C., China A.M., Farole T., Vințan A., Park J., Garrett K.P., Ionescu-Heroiu M. (2017), Orașe-magnet: migrație şi navetism în România (Magnet cities: migration and commuting in Romania),World Bank Group (Washington DC, USA). [Book in Romanian]. ISBN: 978-973-0-24660-5.

DeFries R. S., Rudel T., Uriarte M., Hansen M. (2010), Deforestation driven by urban population growth and agricultural trade in the twenty-first century. Nature Geoscience, 3 (3), 178-181. DOI: https://doi.org/10.1038/ngeo756

Engelke, D., Vancutsem, D. (2010), Sustainable Land Use Management in Europe. Providing strategies and tools for decision-makers. Certu Publications Department.

Frenkel A., Ashkenazi M. (2008), Measuring urban sprawl: How can we deal with it? Environment and Planning B: Planning and Design, 35 (1), 56-79. DOI: https://doi.org/10.1068/b32155.

García P., Pérez E. (2016), Mapping of soil sealing by vegetation indexes and built-up index: A case study in Madrid (Spain). Geoderma, 268, 100-107. DOI: https://doi.org/10.1016/j.geoderma.2016.01.012.

Gomarasca M.A., Brivio P.A., Pagnoni F., Galli A. (1993), One century of land use changes in the metropolitan area of Milan (Italy). International Journal of Remote Sensing, 14(2), 211-223. DOI: 10.1080/01431169308904333.

Grimm N. B., Grove J. M., Pickett S. T. A., Redman C. L. (2000), Integrated Approaches to Long-Term Studies of Urban Ecological Systems: Urban ecological systems present multiple challenges to ecologists-pervasive human impact and extreme heterogeneity of cities, and the need to integrate social and ecological approaches, concepts, and theory. BioScience, 50 (7), 571-584. DOI:https://doi.org/ 10.1641/ooo6-3568(2000)050 [0571:IATLTO]2.0.CO;2 Huete A. R. (1988), A soil-adjusted vegetation index (SAVI). Remote Sensing of Environment, 25, 295-309. DOI: 10.1016/0034-4257(88)90106-X.

Huzui A. E., Abdelkader A., Pătru-Stupariu, I. (2013), Analyzing urban dynamics using multitemporal satellite images in the case of a mountain area, Sinaia (Romania). International Journal of Digital Earth, 6 (6), 563-579. DOI: https://doi.org/10.1080/ 17538947.2011.642901

Ionescu-Heroiu M., Neagu M., Burduja S., Sandu D., Moldovan C., Man T., Rusu R. (2013a), Growth Poles - The Next Phase. World Bank. Washington DC.

Ionescu-Heroiu M., Burduja S., Sandu D., Cojocaru Ş., Blankespoor B., Iorga E., Moretti E., Moldovan C., Man T., Rusu R., Van der Weide R. (2013b), Competitive Cities. Reshaping the Economic Geography of Romania. World Bank. Washington DC.

Jiang L., Deng X., Seto K. C. (2012), Multi-level modeling of urban expansion and cultivated land conversion for urban hotspot counties in China. Landscape and Urban Planning, 108 (2), 131-139. DOI: https://doi.org/10.1016/j.landurbplan.2012.08.008 
Jiang L., O'Neill B. C. (2018), Determinants of Urban Growth During Demographic and Mobility Transitions: Evidence from India, Mexico, and the US. Population and Development Review, 44 (2), 363-389. DOI: https://doi.org/10.1111/padr.12150.

Jiao L. (2015), Urban land density function: A new method to characterize urban expansion. Landscape and Urban Planning, 139, 26-39. DOI: https://doi.org/10.1016/j.landurbplan.2015.02.017.

Kantakumar L. N., Kumar S., Schneider K. (2016), Spatiotemporal urban expansion in Pune metropolis, India using remote sensing. Habitat International, 51, 11-22. DOI: https://doi.org/10.1016/ j.habitatint.2015.10.007.

Li B., Chen D., Wu S., Zhou S., Wang T., Chen H. (2016), Spatio-temporal assessment of urbanization impacts on ecosystem services: case study of Nanjing City, China. Ecological Indicators, 71, 416-427. DOI: https://doi.org/10.1016/j.ecolind.2016.07.017

Li X., Zhou W., Ouyang Z. (2013), Forty years of urban expansion in Beijing: What is the relative importance of physical, socioeconomic, and neighbourhood factors? Applied Geography, 38 (1), 110. DOI: https://doi.org/10.1016/j.apgeog.2012.11.004

Mancebo F. (2008), Coping with urban sprawl: toward a sustainable peri-urbanization, giving way to residential path. Les Annales de la Recherche Urbaine, PUCA, 51-57.

Markham B. L., Storey J. C., Williams D. L., Irons J. R. (2004), Landsat sensor performance: history and current status. IEEE Transactions on Geoscience and Remote Sensing, 42(12), 2691-2694. DOI: $10.1109 /$ TGRS.2004.840720

National Institute of Statistics Romania (NIS) (2018), Social and economic statistics. URL: http://statistici.insse.ro:8077/tempo-online/\#/pages/ tables/insse-table.

Osgouei P. E., Kaya S. (2017), Analysis of land cover/use changes using Landsat 5 TM data and indices. Environmental Monitoring and Assessment, 189(4):136. DOI: $10.1007 /$ s10661-017-5818-5.

Parece T. E., Campbell J. B. (2013), Comparing urban impervious surface identification using Landsat and high resolution Aerial photography. Remote Sensing, 5(10), 4942-4960. DOI: https://doi.org/ 10.3390 / rs5104942.

Pickett S. T. A., Cadenasso M. L., Grove J. M., Boone C. G., Groffman P. M., Irwin E., Nilon C.H. (2011), Urban ecological systems: Scientific foundations and a decade of progress. Journal of Environmental Management, 92 (3), 331-362. DOI: https://doi.org/10.1016/j.jenvman.2010.08.022.

Rojas C., Pino J., Basnou C., Vivanco M. (2013), Assessing land-use and -cover changes in relation to geographic factors and urban planning in the metropolitan area of Concepción (Chile). Implications for biodiversity conservation. Applied Geography, 39, 93103. DOI: https://doi.org/10.1016/j.apgeog.2012. 12.007. Seto K. C., Fragkias M., Güneralp B., Reilly M. K. (2011), A Meta-Analysis of Global Urban Land Expansion. PLoS One, 6 (8). DOI: https://doi.org/ 10.1371/journal.pone.0023777.

Song W., Pijanowski B.C., Tayyebi A. (2015), Urban expansion and its consumption of high-quality farmland in Beijing, China. Ecological Indicators, 54, 60-70. DOI: https://doi.org/10.1016/j.ecolind.2015.02.015.

Suditu B., Ginavar A., Muică A., Iordăchescu C., Vârdol A., Ghinea B. (2010), Urban sprawl characteristics and typologies in Romania. Journal of Studies and Research in Human Geography, 4 (2), 79-87.

Thyagharajan K. K., Vignesh, T. (2017), Soft Computing Techniques for Land Use and Land Cover Monitoring with Multispectral Remote Sensing Images: A Review. Archives of Computational Methods in Engineering. DOI 10.1007/s11831-017-9239-y.

Vaz E., Nijkamp P. (2015), Gravitational forces in the spatial impacts of urban sprawl: An investigation of the region of Veneto, Italy. Habitat International, 45, 99-105. DOI: https://doi.org/10.1016/j.habitatint.2014.06. 024

Wang J., Zhou W., Pickett S. T. A., Yu W., Li W. (2019), A multiscale analysis of urbanization effects on ecosystem services supply in an urban megaregion. Science of the Total Environment, 662, 824-833. DOI: 10.1016/j.scitotenv.2019.01.260.

Wang L., Pijanowski B., Yang W., Zhai R., Omrani H., Li K. (2018), Predicting multiple land use transitions under rapid urbanization and implications for land management and urban planning: the case of Zhanggong District in central China. Habitat International, 82, 48-61. DOI: https://doi.org/10.1016/ j.habitatint.2018.08.007.

Xu H. Q. (2008), A new index for delineating built-up land features in satellite imagery. International Journal of Remote Sensing, 29 (14), 4269-4276. DOI: https://doi.org/10.1080/01431160802039957.

Zha Y., Gao J., Ni S. (2003), Use of normalized difference built-up index in automatically mapping urban areas from TM imagery. International Journal of Remote Sensing, 24, 583-594. DOI: https://doi.org/ 10.1080/01431160304987.

Zhang D., Huang Q., He C., Wu J. (2017), Impacts of urban expansion on ecosystem services in the BeijingTianjin-Hebei urban agglomeration, China: a scenario analysis based on the shared socioeconomic pathways. Resources, Conservation and Recycling, 125, 115-130. DOI: https://doi.org/10.1016/j.resconrec.2017. 06.003.

Zhou D., Tian Y., Jiang G. (2018), Spatio-temporal investigation of the interactive relationship between urbanization and ecosystem services: case study of the Jingjinji urban agglomeration, China. Ecological Indicators, 95, 152-164. DOI: https://doi.org/10.1016 /j.ecolind.2018.07.007. 